Research Article

\title{
The Inhibition Effects of Shenmai Injection on Acetylcholine-Induced Catecholamine Synthesis and Secretion by Modulating Nicotinic Acetylcholine Receptor Ion Channels in Cultured Bovine Adrenal Medullary Cells
}

\author{
Xiting Zhang $\mathbb{D}^{1,2,3,4}$ Lin Li $\mathbb{D}^{1,1,2,3,4}$ Yi Wang $\mathbb{D}^{1,2,3,4}$ Haoping Mao $\mathbb{D}^{1,1,2,3,4}$ \\ Lijuan Chai $\mathbb{D}^{1,2,3,4}$ Lin Miao $\mathbb{D}^{1,2,3,4}$ Shuang Wang $\mathbb{D}^{1,2,3,4}$ Xiumei Gao $\mathbb{D}^{1,2,3,4}$ \\ and Han Zhang ${ }^{1,2,3,4}$ \\ ${ }^{1}$ Institute of Traditional Chinese Medicine, Tianjin University of Traditional Chinese Medicine, Tianjin 301617, China \\ ${ }^{2}$ State Key Laboratory of Component-Based Chinese Medicine, Tianjin University of Traditional Chinese Medicine, \\ Tianjin 301617, China \\ ${ }^{3}$ Key Laboratory of Pharmacology of Traditional Chinese Medical Formulae, Tianjin University of Traditional Chinese Medicine, \\ Ministry of Education, Tianjin 301617, China \\ ${ }^{4}$ Laboratory of Pharmacology of TCM Formulae Co-Constructed by the Province-Ministry, \\ Tianjin University of Traditional Chinese Medicine, Tianjin 301617, China
}

Correspondence should be addressed to Haoping Mao; haoping_mao@126.com and Han Zhang; zhanghan0023@126.com

Received 22 April 2020; Revised 10 August 2020; Accepted 5 December 2020; Published 15 December 2020

Academic Editor: Man Hee Rhee

Copyright ( 92020 Xiting Zhang et al. This is an open access article distributed under the Creative Commons Attribution License, which permits unrestricted use, distribution, and reproduction in any medium, provided the original work is properly cited.

\begin{abstract}
Shenmai injection (SMI) has been widely used for the treatment of cardiovascular diseases in China. Cardiovascular disorders are often related to excessive catecholamine (CA) secretion. Here, we report the effects of SMI on CA secretion and synthesis in cultured bovine adrenal medullary cells. We found that SMI significantly reduced CA secretion induced by $300 \mu \mathrm{M}$ acetylcholine (ACh). Cotreatment with SMI $(10 \mu \mathrm{L} / \mathrm{mL})$ and either of the ACh receptor $\alpha$-subunit inhibitors, $\operatorname{HEX}(\alpha 3)$ or $\mathrm{Dh} \beta \mathrm{E}(\alpha 4 \beta 2)$, did not produce any further inhibition, indicating that SMI may play a role through $\alpha 3$ and $\alpha 4 \beta 2$ channels. Furthermore, SMI reduced tyrosine hydroxylase (TH) activity induced by ACh by inhibiting the phosphorylation of TH at Ser19 and Ser40. TH is phosphorylated at Ser 19 by Ca $^{2+} /$ calmodulin-dependent protein kinase II (CaM kinase II) and at Ser40 by protein kinase $A$ (PKA). KN-93 and H89, the antagonists of CaM kinase II and PKA, respectively, inhibited the ACh-induced phosphorylation at Ser19 and Ser40, and the addition of SMI did not augment the inhibitory effect. Taken together, our results show that SMI likely inhibits CA secretion by blocking TH activity at its Ser19 and Ser40 sites.
\end{abstract}

\section{Introduction}

Catecholamines (CAs) are a class of neurotransmitters including norepinephrine (NE), epinephrine (E), and dopamine (DA). CAs regulate normal cardiovascular functions at physiological levels, while excessive secretion can aggravate cardiovascular diseases such as heart failure, atherosclerosis, coronary heart disease, hypertension, and so on [1].

Bovine adrenal chromaffin cells, also called adrenal medullary cells, were derived from embryonic neural crests with homologous function in sympathetic neurons [2]. Hence, bovine adrenal medullary cells were widely used to detect the effect of various medicines or chemicals on catecholamine secretion and synthesis. Researchers found that there are at least three distinct types of ionic channels that participate in catecholamine secretion, including nicotinic acetylcholine receptor (nAChR) ion channels, voltage-dependent $\mathrm{Na}^{+}$channels, and voltage-dependent $\mathrm{Ca}^{2+}$ channels [3]. In cultured bovine adrenal medullary cells, Ach and veratridine were reported to be activators of the nicotinic 
acetylcholine receptor and voltage-dependent $\mathrm{Na}^{+}$channels, respectively. Both $\mathrm{ACh}$ and veratridine caused $\mathrm{Na}^{+}$influx and depolarization of membrane after they acted with the above receptors [4]. Then, depolarization of membrane could cause the opening of voltage-dependent $\mathrm{Ca}^{2+}$ channels. Besides, high $\mathrm{K}^{+}(\mathrm{HK})$ directly activated voltage-dependent $\mathrm{Ca}^{2+}$ channels to increase $\mathrm{Ca}^{2+}$ influx without increasing $\mathrm{Na}^{+}$influx [5]. $\mathrm{Ca}^{2+}$ influx is the essential trigger for CA synthesis and secretion [6]. It was found that the final raise of introcellular $\left(\mathrm{Ca}^{2+}\right)$ induced by $\mathrm{ACh}$, Ver, and HK induced the secretion of catecholamine. On the other hand, it was known that biosynthesis of CA began with dihydroxyphenylalanine (DOPA) which was converted to dopamine (DA); the latter was then modified into norepinephrine (NE) and epinephrine (E) [7]. Tyrosine hydroxylase $(\mathrm{TH})$, which catalyzed the rate-limiting step in catecholamine biosynthesis [8], was activated via phosphorylation at the Ser19, Ser31, and Ser40 sites in correspondence to following multiple protein kinases, including $\mathrm{Ca}^{2+} /$ calmodulin-dependent protein kinase II (CaM kinase II), extracellular signal-regulated protein kinase (ERK), and cAMP-dependent protein kinase A (PKA) $[9,10]$.

Shenmai injection (SMI), based on the traditional Chinese prescriptions of Shenmai San that was recorded in the 1186 $\mathrm{AD}$ "Yixue qiyuan" account of Zhang Yuansu, was approved by China Food and Drug Administration (CFDA) for the treatment of heart failure in 1995 [11]. Consisting of aqueous extracts from Panax ginseng C.A. Mey (Renshen) and Ophiopogon japonicus (Thunb.) Ker Gawl. (Maidong), its chemical fingerprinting has been established by high-performance liquid chromatography (HPLC) [12], and the main pharmacological active components are ginsenoside Rgl, ginsenoside Rg2, ginsenoside Rg3, ginsenoside Re, ginsenoside $\mathrm{Rb} 1$, and ophiopogonin $D[13,14]$. It has been widely used for hypertension, coronary heart diseases, stroke, chronic pulmonary heart disease, viral myocarditis, heart and respiratory failure, cerebral infarction, and malignant diseases [15-17].

Although toxicity studies have confirmed the general safety of SMI $[18,19]$, its effects and mechanisms on catecholamine secretion and synthesis have not been fully investigated. Therefore, in the current study, bovine adrenal medullary cells were used to investigate the effect and the potential mechanisms of SMI on CA synthesis and secretion. First, we primary cultured the bovine adrenal medullary cells and established the ACh, Ver, and HK-induced CA secretion model to investigate the effect of SMI on CA secretion by using HPLC coupled with the electrochemical detection (HPLC-ECD) method and introcellular $\mathrm{Ca}^{2+}$ by an inverted fluorescent microscope. Then, we used the inhibitors of corresponding subunits of $\mathrm{nAChR}$ to confirm in which subunits of the channels did SMI exerts its effects on inhibiting $\mathrm{Ca}^{2+}$ influx and CA secretion. Finally, we detected the effects of SMI on the activity of $\mathrm{TH}$ and its possible phosphorylation sites to investigate the effect and mechanism on CA synthesis.

\section{Materials and Methods}

2.1. Materials. SMI was purchased from CTQ Pharmaceutical Group Co., Ltd. (Hangzhou, China) according to the guidelines of Good Manufacturing Practice and Good Laboratory Practice. Oxygenated Krebs-Ringer phosphate (KRP) buffer was prepared using $154 \mathrm{mM} \mathrm{NaCl}, 5.6 \mathrm{mM}$ $\mathrm{KCl}, 1.1 \mathrm{mM} \mathrm{MgSO}_{4}, 2.2 \mathrm{mM} \mathrm{CaCl}_{2}, 0.85 \mathrm{mM} \mathrm{NaH}_{2} \mathrm{PO}_{4}$, and $2.15 \mathrm{mM} \mathrm{Na}_{2} \mathrm{HPO}_{4}$ with $\mathrm{pH}$ adjusted to 7.4. Eagle's minimum essential medium (Eagle's MEM) was purchased from Coring (New York, USA), and fetal calf serum (FCS) was sourced from Australia. Methyllycaconitine citrate (MLA) and dihydro- $\beta$-erythroidine hydrobromide $(\mathrm{DH} \beta \mathrm{E})$ were obtained from Merck Millipore (Massachusetts, USA) and RD (San Francisco, USA), respectively. Hexamethonium bromide (HEX), KN-93, and H89 were purchased from MCE (Shanghai, China). Antibodies against phosphorylated TH were obtained from Jianshu, China ( $\mathrm{p}$ THSer19 and p-THSer40), and Cell Signaling Technology (Boston, USA) (p-THSer31 and $\beta$-actin). The Pierce BCA Protein Assay Kit was purchased from Thermo (Waltham, MA, USA). Acetylcholine chloride (ACh), veratridine, and potassium chloride were obtained from Sigma (St. Louis, MO, USA). The cell culture reagents trypsin inhibitor, collagenase $L$, and penicillin-streptomycin and collagenase type 1 were purchased, respectively, from Nacalai Tesque (Kyoto, Japan), Wako (Kyushu, Japan), and Gibco (California, CA, USA). Finally, the TH activity detection kit was purchased from Genmed (Shanghai, China) and Fluo4-AM from Dojindo (Kyushu, Japan).

2.2. Isolation and Primary Culture of Bovine Adrenal Medullary Cells. Bovine adrenal glands were obtained from the City Slaughter House. The chromaffin cells were isolated from the adrenal glands by collagenase digestion as described previously [20]. The cells were cultured at a density of $5 \times 10^{5}$ cells/well in Eagle's MEM supplemented with $10 \%$ FCS, $50 \mathrm{U} / \mathrm{mL}$ penicillin, and $50 \mathrm{~g} / \mathrm{mL}$ amphotericin $B$ under a humidified atmosphere of $5 \% \mathrm{CO}_{2}$ and $95 \%$ air at $37^{\circ} \mathrm{C}$ in 12-well, 24-well, and 48-well plates. Primary cells harvested between 2 and 5 days of culture were used for experiments.

2.3. Catecholamine Secretion from Cultured Bovine Adrenal Medullary Cells. To detect the effect of SMI on CA secretion, the level of CAs in culture medium was detected by the highperformance liquid chromatographic system coupled with an electrochemical detector (HPLC-ECD). Briefly, bovine adrenal medullary cells were buffered with oxygenated KRP and washed 3 times before experiments. After incubation with the indicated agents at $37^{\circ} \mathrm{C}$ for $10 \mathrm{~min}$, the medium was transferred immediately to a test tube containing perchloric acid (PCA) (final concentration, $0.4 \mathrm{M}$ ), and NE and $E$ secreted into the medium were detected by HPLC-ECD. The chromatographic separation system included a RP-C18 analytical column $(5 \mu \mathrm{m}, \varphi 4.6 \mathrm{~mm} \times 250 \mathrm{~mm})$ and an isocratic solvent system. The flow phase $(1 \mathrm{~L})$ contained $100 \mathrm{~mL}$ acetonitrile, $100 \mu \mathrm{L}$ triethylamine, $13.6 \mathrm{~g} \mathrm{KH}_{2} \mathrm{PO}_{4}, 2.5 \mathrm{~g}$ octane-sulfonic acid sodium, and $0.036 \mathrm{~g}$ EDTA, $\mathrm{pH}$ adjusted to 3 with $\mathrm{H}_{3} \mathrm{PO}_{4}$. The flow rate was $0.6 \mathrm{~mL} / \mathrm{min}$, column temperature was $30^{\circ} \mathrm{C}$, and sample injection volume was $10 \mu \mathrm{L}$. An electrochemical detector with two channels $(0 \mathrm{mV}$ and $+300 \mathrm{mV})$ was used to detect the signals. 
Chromaffin cells were buffered with $\mathrm{Ca}^{2+} \mathrm{KRP}$ and washed 3 times before experiments. After $10 \mathrm{~min}$ preincubation with different dilutions of SMI, cells were incubated for an additional $10 \mathrm{~min}$ in the presence or absence of various secretagogues. The incubation medium was then transferred immediately to a test tube containing perchloric acid (PCA) (final concentration, $0.4 \mathrm{M}$ ). NE and $E$ secreted into the medium were directly injected and detected by HPLC-ECD as described above.

2.4. Measurement of Intracellular $\mathrm{Ca}^{2+}$ Mobilization. To examine the effects of SMI on intracellular $\mathrm{Ca}^{2+}$ concentration induced by $300 \mu \mathrm{M} \mathrm{ACh}$, cells were seeded into black-walled clear-base 96-well plates (CORING, USA) in culture media and cultured for approximately $24 \mathrm{~h}$ in a $37^{\circ} \mathrm{C}$ $\mathrm{CO}_{2}$ incubator. The culture media was removed, and the cells were washed with KRP buffer three times. The cells were then incubated with $2 \mu \mathrm{M}$ Fluo4-AM for $20 \mathrm{~min}$ at $37^{\circ} \mathrm{C}$ and then washed three times with $\mathrm{Ca}^{2+}(+) \mathrm{KRP}$ buffer. After a final incubation in KRP buffer for $20 \mathrm{~min}$ at $37^{\circ} \mathrm{C}$, changes in fluorescence induced by the Fluo 4 complex was measured at an excitation wavelength of $494 \mathrm{~nm}$ and an emission wavelength of $516 \mathrm{~nm}$ before and after the addition of SMI $(0.25-1 \mu \mathrm{L} / \mathrm{mL}$ ), with a microplate reader (SpectraMax 190, Molecular Devices, USA), and the cells were observed by an inverted fluorescent microscope (DM750 M, LEICA, Germany) at 20x amplified.

2.5. In Situ Detection of TH Activity. The cells cultured at a density of approximately $1 \times 10^{7}$ cells per well were washed three times with PBS buffer. Then, the cells were incubated with the TH activity detection kit according to the manuscript's instructions. The TH activity was measured in terms of fluorescence $(e x=280 \mathrm{~nm}$, em $=320 \mathrm{~nm}$ ) by a microplate reader.

2.6. In Situ Phosphorylation of TH. The effect of SMI on the inhibition of phospho-Ser19, phospho-Ser31, and phosphoSer40 of TH was assayed by SDS-polyacrylamide gel electrophoresis (SDS-PAGE) and Western blot analysis. Cells $\left(2 \times 10^{6} /\right.$ dish $)$ were incubated with or without SMI $(0.25-1 \mu \mathrm{L} / \mathrm{mL})$ for $20 \mathrm{~min}$ in KRP buffer. The cells were washed twice with ice-cold KRP buffer, lysed in lysis buffer, and the lysates were centrifuged at $15,000 \mathrm{x} g$ for $30 \mathrm{~min}$.

Protein concentration was measured using an enhanced BCA Protein Assay Kit, and equal amounts of protein were mixed with $5 x$ SDS-PAGE sample loading buffer. Following heating at $95^{\circ} \mathrm{C}$ for $5 \mathrm{~min}$, proteins were subjected to $10 \%$ Tris-glycine gel SDS-PAGE and transferred electrophoretically to polyvinylidene difluoride membranes (BioRad). The membranes were incubated with the primary antibodies (1: 1000 ) overnight at $4^{\circ} \mathrm{C}$ and then washed with phosphatebuffered saline containing $0.1 \%$ Tween 20 (PBS-T), followed by incubation with the rabbit radish-peroxidase-labeled secondary antibody $(1: 10000)$ at room temperature for $1 \mathrm{~h}$. The protein bands were visualized using enhanced chemiluminescence by Western blot detection reagents, and the band densities were measured by Quantity One software using the Versa Doc imaging system (BioRad). Data were expressed as the ratio of phosphorylated proteins to total proteins.

2.7. Statistical Analysis. All experiments were performed in triplicates, and each experiment was repeated at least 3 times. The data were presented as mean \pm SEM. Statistical significance was evaluated using the $t$-test or one-way analysis of variance (ANOVA), and $p<0.05$ was considered significant. All statistical analyses were performed using SPSS 11.5 software (SPSS Inc., Chicago, IL, USA).

\section{Results}

3.1. Effect of SMI on Basal and Secretagogue-Induced CA Secretion in Cultured Bovine Adrenal Medullary Cells. To study the effect of SMI on CA secretion, bovine adrenal medullary cells were treated with various secretagogues in the presence or absence of SMI $(2.5 \mu \mathrm{L} / \mathrm{mL})$. SMI did not affect the basal CA secretion in the control group that treated with no secretagogue $(p>0.05)$. Upon cotreatment with different secretagogues for $10 \mathrm{~min}, 2.5 \mu \mathrm{g} / \mathrm{mL}$ SMI significantly inhibited CA secretion induced by $300 \mu \mathrm{M}$ ACh $(p<0.05)$ and caused a slight decline in $56 \mathrm{mM} \mathrm{K}^{+}$and $100 \mathrm{mM}$ Ver-induced secretion $(p>0.05)$ (Figure $1(\mathrm{a}))$. We also examined the effect of SMI on CA secretion induced by $300 \mu \mathrm{M}$ ACh. Cells treated with $2.5,5$, and $10 \mu \mathrm{L} / \mathrm{mL}$ SMI for 10 min showed significantly reduced $\mathrm{ACh}$-induced secretion of CA $(p<0.05$ and $p<0.01)$ compared to Ach-treated cells only (Figure 1(b)).

3.2. Inhibitory Role of SMI on Catecholamine Secretion Induced by $300 \mu \mathrm{M}$ ACh. The nAChR ion channels consist of three important $\alpha$-subunit sites $-\alpha 3, \alpha 4 \beta 2$, and $\alpha 7$. To examine the involvement of voltage-dependent $\mathrm{nAChR}$ ion channels on the SMI effect, we treated the cells with specific inhibitors against the $\alpha$-subunit, namely, $\operatorname{HEX}(\alpha 3), \operatorname{Dh} \beta \mathrm{E}$ $(\alpha 4 \beta 2)$, and MLA $(\alpha 7)$.

After 10 min pretreatment with (or without) SMI $(10 \mu \mathrm{L} /$ $\mathrm{mL})$, cells were cotreated with $300 \mu \mathrm{M}$ ACh and $\operatorname{HEX}(10 \mu \mathrm{M})$, $\operatorname{Dh} \beta \mathrm{E}(10 \mu \mathrm{M})$, or MLA $(10 \mu \mathrm{M})$ for $10 \mathrm{~min}$ at $37^{\circ} \mathrm{C}$; suitable untreated controls were included. As shown in Figure 2, HEX, $\mathrm{Dh} \beta \mathrm{E}$, and MLA each inhibited ACh-induced CA secretion $(p<0.05)$. The inhibitory effect of MLA was further augmented in the presence of SMI $(p<0.05)$, while HEX and $\mathrm{DH} \beta \mathrm{E}$ did not further increase the inhibitory effects of SMI.

3.3. Inhibition of SMI upon Increased $\mathrm{Ca}^{2+}$ Influx Induced by $300 \mu M$ Ach in Bovine Adrenal Medullary Cells. In order to further validate the inhibitory effect of SMI on $\mathrm{nAChR}$ ion channels, different concentrations of SMI $(2.5,5$, and $10 \mu \mathrm{L} /$ $\mathrm{mL}$ ) were used to increase $\mathrm{Ca}^{2+}$ influx induced by $300 \mu \mathrm{M}$ $\mathrm{ACh}$, and the intracellular $\mathrm{Ca}^{2+}$ concentrations were measured. SMI significantly suppressed the ACh-induced $\mathrm{Ca}^{2+}$ influx, which is consistent with the results of CA secretion (Figure 3). 


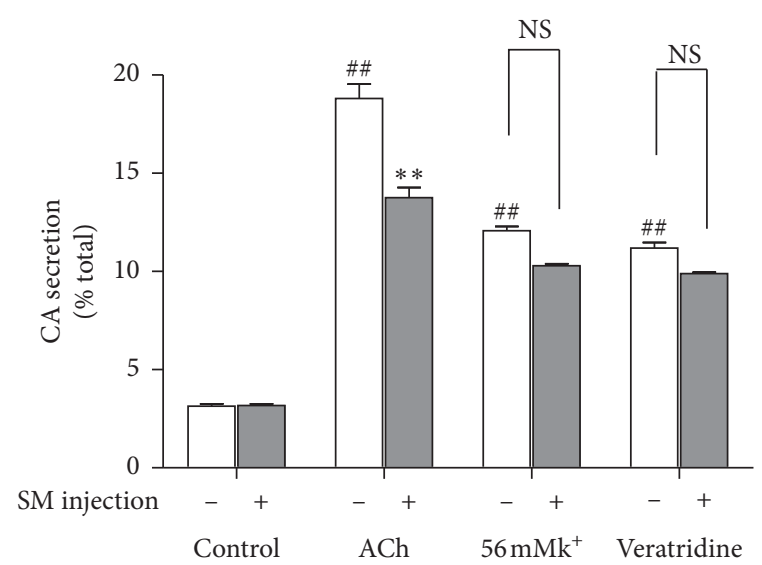

(a)

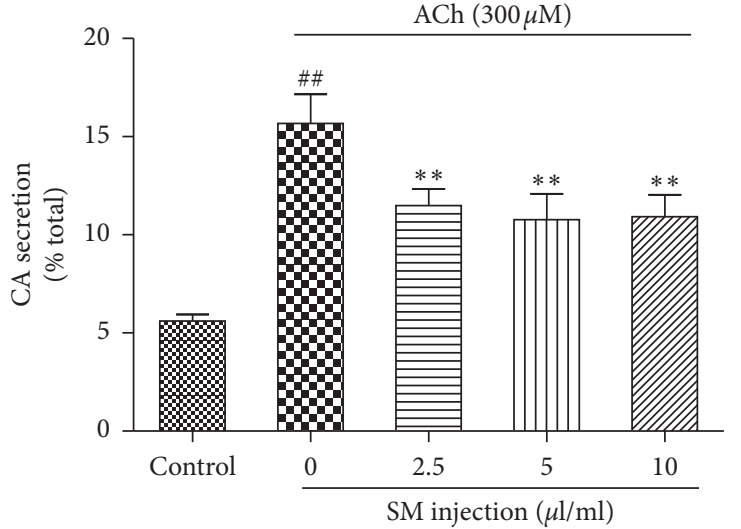

(b)

FIGURE 1: The effects of SMI on CA secretion in bovine adrenal medullary cells. (a) Effects of $2.5 \mu \mathrm{L} / \mathrm{mL}$ SMI on basal CA secretion and on various secretagogue agonists induced CA secretion. (b) Effects of SMI on CA secretion induced by $300 \mu \mathrm{M}$. Data are expressed in mean \pm SEM based on three independent experiments each performed in triplicates $\left(n=6\right.$ per group). ${ }^{* *} p<0.01$ compared with ACh alone. $\#$ \#\# 0.01 compared with untreated control.

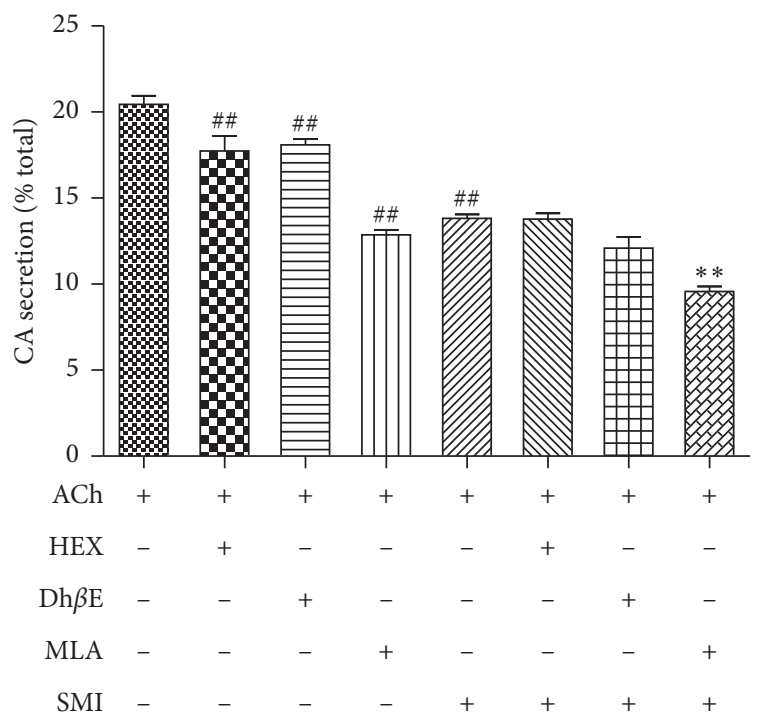

FIGURE 2: Effects of combinations of SMI and several inhibitors of $\alpha$-subunit sites in the nAChR ion channels on catecholamine secretion induced by $300 \mu \mathrm{M}$ ACh. Data are expressed as mean\pm SEM based on three independent experiments each performed in triplicates ( $n=6$ per group). ${ }^{\# \#} p<0.01$, compared with $300 \mu \mathrm{M}$ ACh alone and ${ }^{* *} p<0.01$, compared with $300 \mu \mathrm{M}$ ACh plus SMI.

3.4. Effects of SMI on ACh-Induced Activity of Tyrosine Hydroxylase. We next examined the effect of SMI treatment on ACh-induced TH activity. Cells treated with varying concentrations of SMI $(2.5,5$, and $10 \mu \mathrm{L} / \mathrm{mL})$ for $10 \mathrm{~min}$ at $37^{\circ} \mathrm{C}$ significantly reduced $\mathrm{TH}$ activity induced by $\mathrm{ACh}$ $(p<0.01)$ (Figure 4).

3.5. The Influence of SMI on TH Phosphorylation. To determine which phosphorylated site(s) are affected by SMI, the effect of SMI on TH phosphorylation at the Ser19, Ser31, and Ser40 sites was examined. As shown in Figures 5(b) and
5 (d), cells incubated with SMI $(2.5,5$, and $10 \mu \mathrm{L} / \mathrm{mL})$ for $20 \mathrm{~min}$ at $37^{\circ} \mathrm{C}$ showed a significant decrease in phosphorylation at Ser19 and Ser40 $(p<0.05, p<0.01)$, but not at Ser31 (Figure 5(c)). TH is phosphorylated at Ser19 by CaM kinase II and at Ser40 by PKA. To determine the possible mechanism of the antiphosphorylation effect of SMI, cells were treated with $10 \mu \mathrm{M}$ KN-93, a CaM kinase II antagonist, and $10 \mu \mathrm{M} \mathrm{H} 89$, a PKA antagonist. While both antagonists significantly suppressed the stimulatory effect of $300 \mu \mathrm{M}$ ACh on TH activity $(p<0.05)$, addition of SMI $(10 \mu \mathrm{L} / \mathrm{mL})$ did not augment the inhibitory effect of either KN-93 or H89 (Figures 5(g) and 5(h)).

\section{Discussion}

In the present study, we found that SMI reduced the CA secretion induced by ACh in adrenal medullary cells, while it had no effect on veratridine and HK-induced catecholamine secretion. We also found that all the three doses of SMI $(2.5 \mu \mathrm{L} / \mathrm{mL}, 5 \mu \mathrm{L} / \mathrm{mL}$, and $10 \mu \mathrm{L} / \mathrm{mL})$ inhibited ACh-induced $\mathrm{Ca}^{2+}$ influx, a prerequisite for the secretion and synthesis of CAs, which was consistent with the results of CA secretion. To the best of our knowledge, this is the first time that SMI mediated inhibition of the function of $\mathrm{nAChR}$ ion channels and CA secretion in cultured bovine adrenal medullary cells.

Nicotinic ACh receptor (nAChR), as an ionotropic receptor, was widely reported to be involved in catecholamine secretion and synthesis [21]. Because of its important role in regulation of the nerve system and involvement in a variety of diseases, $\mathrm{nAChR}$ was well investigated for decades from its structure to the physical functions. It was reported that $\alpha 3$, $\alpha 4 \beta 2$, and $\alpha 7$ as $\mathrm{nAChR}$ ion channels important $\alpha$-subunit sites play an important role on CA secretion. The most relevant $\mathrm{nAChR}$ for $\mathrm{CA}$ secretion is the heteromeric one composed of $\alpha 3$ and $\beta 4$ subunits [22]. The $\alpha 4 \beta 2 \mathrm{nAChR}$ $\mathrm{X}$-ray structure, recently elucidated, because of its heteromeric composition deserves further discussion [23]. A typical $\alpha 7$ agonist like choline was shown to stimulate 


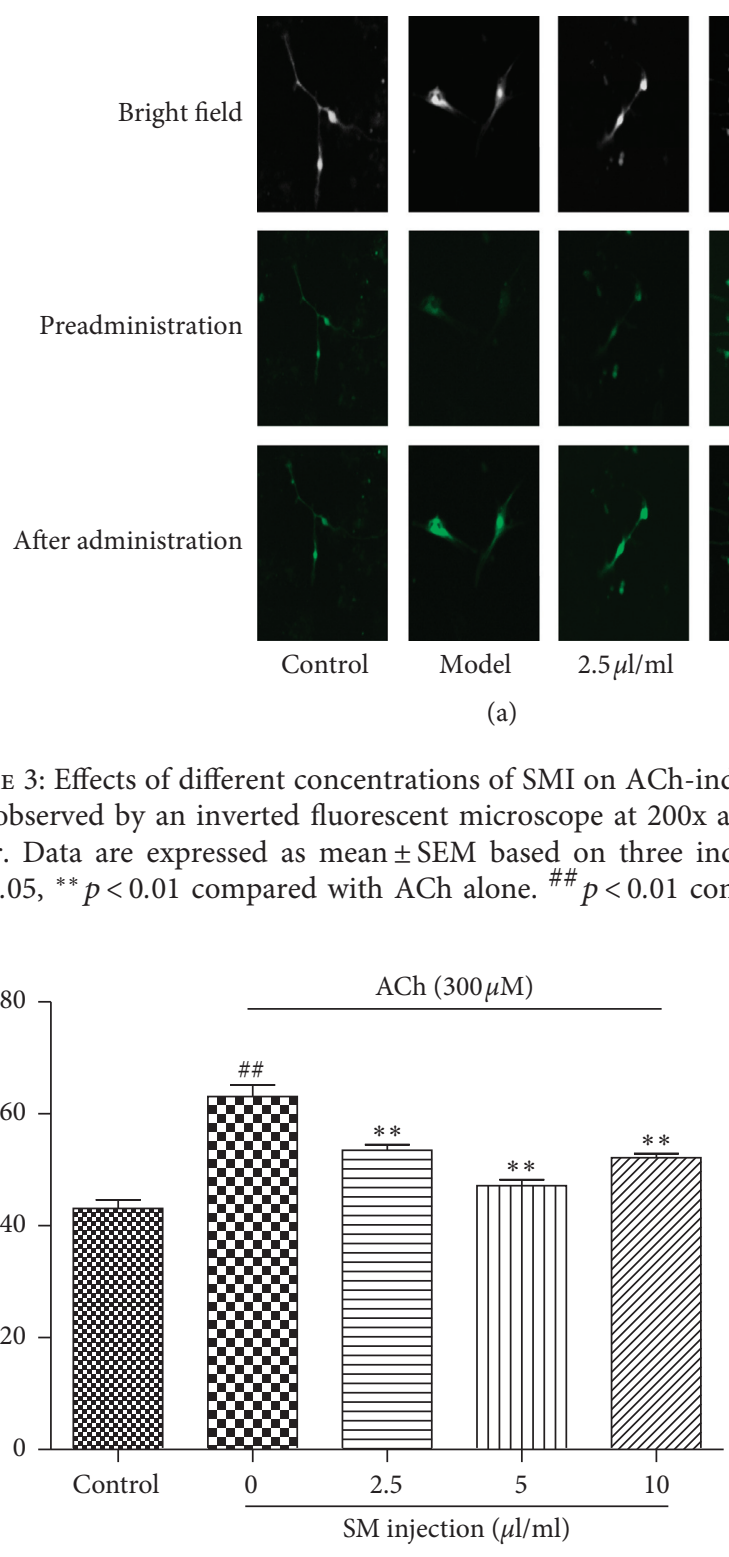

FIGURE 4: Effect of various concentrations of SMI on ACh-induced activity of TH. Data are expressed as mean \pm SEM based on three independent experiments each performed in triplicates $(n=6$ per group). ${ }^{* *} p<0.01$ compared with ACh alone. ${ }^{\# \#} p<0.01$ compared with control.

nAChRs on chromaffin cells to induce catecholamine secretion [24]. Ginsenoside Rg3, a chemical from Panax ginseng, was found to be voltage-dependent to inhibit AChinduced peak inward currents by $\alpha 3 \beta 2, \alpha 3 \beta 4, \alpha 4 \beta 2$, and $\alpha 4 \beta 4$ subunits. However, the same Rg3 effect on $\alpha 7 \mathrm{nAChR}$ channel activity was not observed [25]. It was reported that ginsenoside Rg2, a chemical in SMI, had been shown to block the nicotinic acetylcholine receptors in bovine chromaffin cells by affecting the acetylcholine- (Ach-) induced currents in heteromeric receptors $\alpha 3 \beta 4, \alpha 3 \beta 2, \alpha 4 \beta 4$, and $\alpha 4 \beta 2$, without affecting the acetylcholine- (Ach-) induced currents in $\alpha 7$ human receptors [26]. In the present study, we also found that cotreatment with SMI and the AChR $\alpha 7$ subunit antagonist MLA significantly augmented the inhibition of ACh-induced CA secretion compared to SMI treatment alone, whereas the combination of SMI with $\alpha 3$ and $\alpha 4 \beta 2$ antagonists HEX and $\mathrm{Dh} \beta \mathrm{E}$ did not produce any further inhibition. These data indicated that SMI attenuates ACh-induced CA secretion potentially by preferentially inhibiting $\alpha 3$ and $\alpha 4 \beta 2$ channels with no effect on $\alpha 7$ channel. These results were consistent with the findings in the previous reports on ginsenosides $\mathrm{Rg} 2$ and $\mathrm{Rg} 3$.

Except for the catecholamine secretion, chromaffin cells are also an important method for the catecholamine synthesis study [27]. In our present study, we found that SMI significantly stimulated ACh-induced catecholamine synthesis indicating a possible mechanistic basis of reducing CA secretion. Then, the mechanisms were also detected by testing the effect of SMI on tyrosine hydroxylase (TH) activity. In bovine adrenal medullary cells, $\mathrm{TH}$ catalyzes the conversion of tyrosine to $L$-3,4-dihydroxyphenylalanine (DOPA), the rate-limiting step in CA biosynthesis. Therefore, $\mathrm{TH}$ activity is essential for the synthesis of catecholamine. In the present study, SMI inhibited the ACh-induced $\mathrm{TH}$ activity. It was reported that $\mathrm{TH}$ was regulated by an allosteric activation-induced shortterm regulation and an enzyme induction-induced longterm regulation. TH activity is acutely regulated by various modifications such as phosphorylation [28]. Phosphorylation at Ser40 in TH was essential to active the enzyme, while Ser19 phosphorylation had no direct effect on $\mathrm{TH}$ activity, but it increases $\mathrm{TH}$ activity indirectly by increasing the rate of phosphorylation at Ser40 [29]. So, clarifying the effect of SMI on phosphorylation of TH was important to demonstrate the stimulation of catecholamine synthesis and the TH activity. We found that SMI reduced the levels of phopho-Ser19 following ACh induction, which may likely decrease the phosphorylation rate of Ser40 and eventually decrease TH activity. In this study, KN-93 (an 


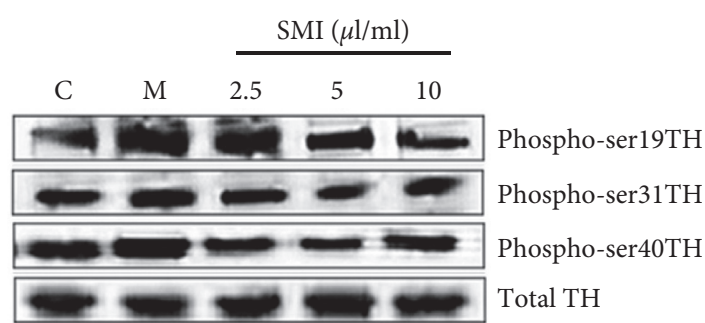

(a)

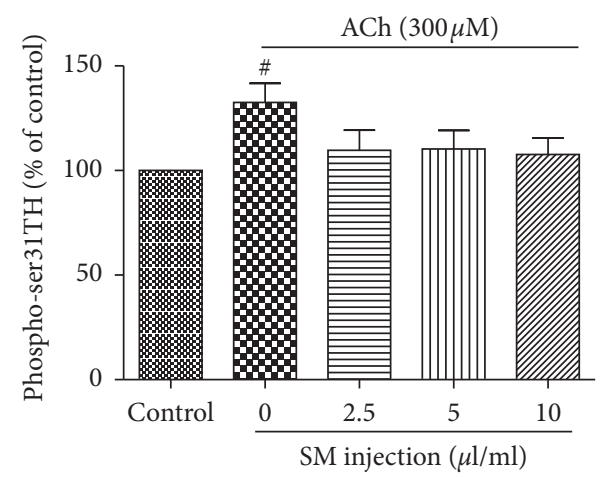

(c)

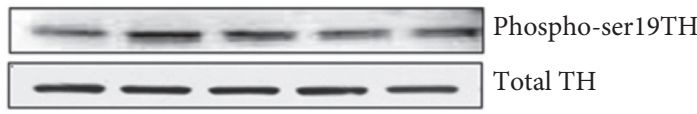

(e)

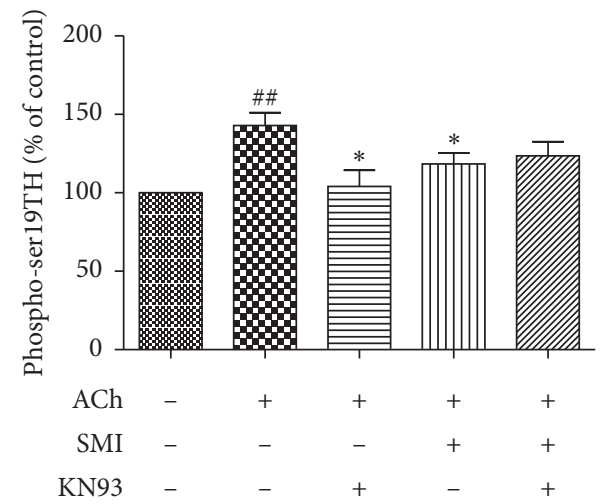

(g)

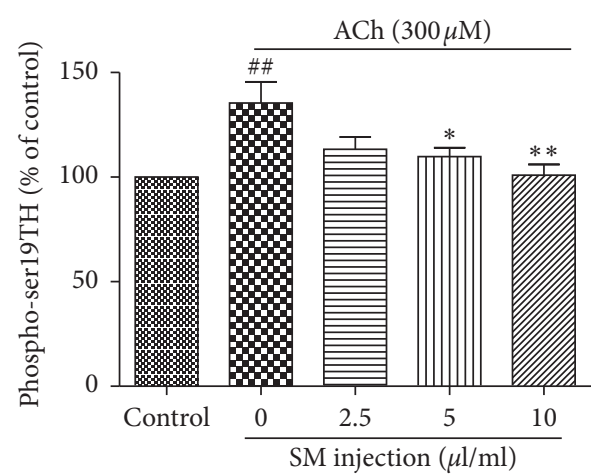

(b)

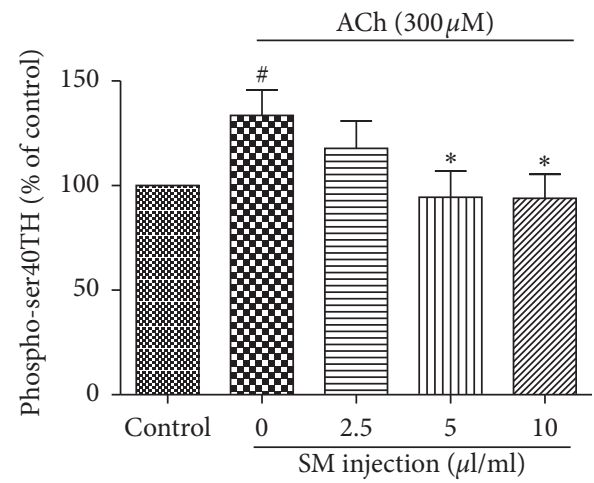

(d)

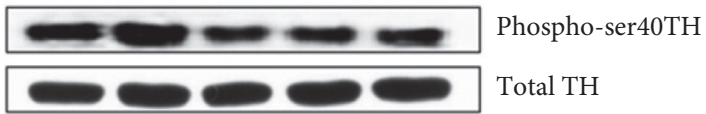

(f)

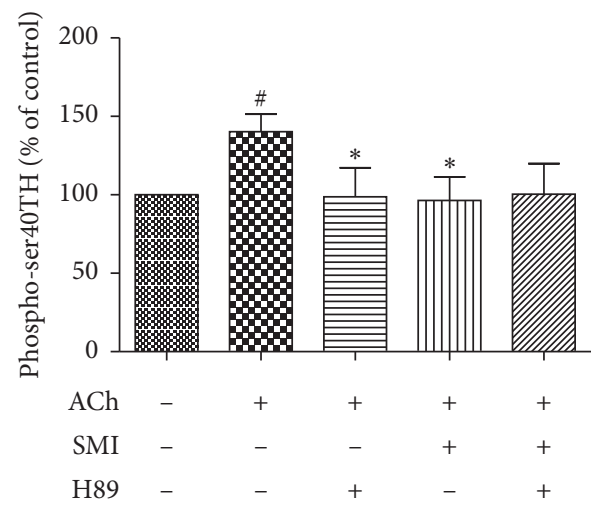

(h)

FIGURE 5: Effect of SMI on TH phosphorylation in bovine adrenal medullary cells. Phosphorylation at the Ser19, Ser31, and Ser40 sites of TH was determined and expressed as \% of control TH band. (a) Effect of SMI on TH phosphorylation at Ser19, Ser31, and Ser40. (b) Effect of SMI on the ratio of the density of TH Ser 19 phosphorylation induced by $300 \mu \mathrm{M}$ ACh. (c) Effect of SMI on the ratio of the density of TH Ser31 phosphorylation induced by $300 \mu \mathrm{M}$ ACh. (d) Effect of SMI on the ratio of the density of TH Ser40 phosphorylation induced by $300 \mu \mathrm{M}$ ACh. ((e), (g)) Effect of SMI and CaM kinase II on phosphorylation of TH Ser19 induced by $300 \mu \mathrm{M}$ ACh. ((f), (h)) Effect of SMI and PKA on phosphorylation of TH Ser40 induced by $300 \mu \mathrm{M}$ ACh. Data are expressed as mean \pm SEM based on three independent experiments each performed in triplicates. ${ }^{*} p<0.05$ and ${ }^{* *} p<0.01$ compared with ACh alone. ${ }^{\#} p<0.05$ and ${ }^{\# \#} p<0.01$ compared with control.

inhibitor of CaM kinase II) and H89 (an inhibitor of protein kinase A) each inhibited the stimulatory effects of ACh on phosphorylation of Ser19 and Ser40, respectively, while SMI addition did not augment the inhibition any further. This result validated our hypothesis that SMI may regulate the phosphorylation of Ser19 and Ser40 to influence TH activity.

Shenmai injection (SMI) has been used extensively in clinical applications to treat cardiovascular diseases. Since excessive secretion of CA plays an important role in 
cardiovascular diseases, it is worth investigating the effect of SMI on the secretory CA system of adrenal medullary cells. CA neurotransmitters such as dopamine (DA), epinephrine (E), and norepinephrine (NE) have vital physiological roles. $\mathrm{NE}$ and $E$ act as central nervous system stimulants resulting in faster heart rate, enhanced myocardial contraction, increased cardiac output, elevated blood pressure, reduced splanchnic blood flow, and increased adipose decomposition and oxidation. Stress is one of the reasons for the increased secretion of calcium synthetic hormones, and chronic stress can trigger abnormal immune functions, high blood pressure, coronary heart disease, and atherosclerosis. Therefore, controlling the synthesis and secretion of CA through drug interventions has immense therapeutic potential. $\mathrm{Ca}^{2+}$ influx is the essential trigger for CA synthesis and secretion, and nicotinic acetylcholine receptor ( $\mathrm{AAChR}$ ) ion channels play an important role in $\mathrm{Ca}^{2+}$ influx. $\alpha 3$ and $\alpha 4 \beta 2$ as $\alpha$-subunit sites of $\mathrm{nAChR}$ ion channels affect its activation. In our study, we found that SMI reduced CA synthesis and secretion induced by ACh, and cotreatment with SMI and the ACh receptor $\alpha$-subunit inhibitors, $\operatorname{HEX}(\alpha 3)$ or $\operatorname{Dh} \beta \mathrm{E}(\alpha 4 \beta 2)$, did not produce any further inhibition, indicating that SMI may reduce CA synthesis and secretion by inhibiting $\alpha 3$ and $\alpha 4 \beta 2$ subunit sites to suppress $\mathrm{AChR}$ ion channels. As a rate-limiting enzyme in the synthesis of CA, the activity of $\mathrm{TH}$ is often tested. TH exerts its effect by phosphorylation at Ser 19 with CaM kinase II and Ser40 with PKA. We found out that SMI suppressed ACh-induced TH activity by inhibiting the phosphorylation of TH at Ser19 and Ser40. KN-93 and H89, the antagonists of CaM kinase II and PKA, respectively, inhibited the ACh-induced phosphorylation at Ser19 and Ser40, and the addition of SMI did not augment the inhibitory effect. These results indicate that SMI inhibits CA secretion by blocking TH activity at Ser19 and Ser40 sites.

The present findings would support the idea that SMI suppresses the CA secretion and synthesis by inhibiting AChR ion channels and TH activity. SMI may also delay the development of cardiovascular disease through the modulation of the sympathetic-adrenal medullary system, primarily by inhibiting the secretion of neurotransmitters at the sympathetic terminals. To confirm this possibility, further in vivo and in vitro studies will be required in near future.

\section{Abbreviations}

$\begin{array}{ll}\text { Ach: } & \text { Acetylcholine } \\ \text { CA: } & \text { Catecholamines } \\ \text { CaM kinase II: } & \mathrm{Ca}^{2+} / \text { calmodulin-dependent protein kinase } \\ & \text { II } \\ \text { DA: } & \text { Dopamine } \\ \text { DH } \beta \text { E: } & \text { Dihydro- } \beta \text {-erythroidine hydrobromide } \\ \text { DOPA: } & \text { Dihydroxyphenylalanine } \\ \text { E: } & \text { Epinephrine } \\ \text { ERK: } & \text { Extracellular signal-regulated protein kinase } \\ \text { HEX: } & \text { Hexamethonium bromide } \\ \text { KRP: } & \text { Oxygenated Krebs-Ringer phosphate } \\ \text { MLA: } & \text { Methyllycaconitine citrate } \\ \text { NE: } & \text { Norepinephrine }\end{array}$

PCA: $\quad$ Perchloric acid

PKA: $\quad$ cAMP-dependent protein kinase A

SMI: $\quad$ Shenmai injections

TH: $\quad$ Tyrosine hydroxylase

Ver: $\quad$ Veratridine.

\section{Data Availability}

The data used to support the findings of this study are available from the corresponding author upon request.

\section{Disclosure}

Xiting Zhang and Lin Li are the co-first authors.

\section{Conflicts of Interest}

The authors declare that there are no conflicts of interest.

\section{Authors' Contributions}

Xiting Zhang and Lin Li contributed equally to the work.

\section{Acknowledgments}

This work was supported by the National Natural Science Foundation of China (Nos. 81630106 and 81973792) and Major State Basic Research Development Program of China (No. 2012CB518404).

\section{References}

[1] L. Jian-Sheng, W. Hai-Feng, L. Su-Yun et al., "Shenmai injection for chronic pulmonary heart disease: a systematic review and meta-analysis," Journal of Alternative and Complementary Medicine, vol. 17, no. 7, pp. 579-587, 2011.

[2] Y. Shinohara, Y. Toyohira, S. Ueno, M. Liu, M. Tsutsui, and N. Yanagihara, "Effects of resveratrol, a grape polyphenol, on catecholamine secretion and synthesis in cultured bovine adrenal medullary cells," Biochemical Pharmacology, vol. 74, no. 11, pp. 1608-1618, 2007.

[3] X. Li, Y. Toyohira, T. Horisita et al., "Ikarisoside A inhibits acetylcholine-induced catecholamine secretion and synthesis by suppressing nicotinic acetylcholine receptor-ion channels in cultured bovine adrenal medullary cells," NaunynSchmiedeberg's Archives of Pharmacology, vol. 388, no. 12, pp. 1259-1269, 2015.

[4] M. Taeko, T. Yumiko, U. Susumu et al., "Simvastatin inhibits catecholamine secretion and synthesis induced by acetylcholine via blocking $\mathrm{Na}^{+}$and $\mathrm{Ca}^{2+}$ influx in bovine adrenal medullary cells," Journal of Pharmacology \& Experimental Therapeutics, vol. 327, no. 1, pp. 130-136, 2008.

[5] M. Haoping, W. Hong, M. Shangwei et al., "Bidirectional regulation of bakuchiol, an estrogenic-like compound, on catecholamine secretion," Toxicology \& Applied Pharmacology, vol. 274, no. 1, pp. 180-189, 2014.

[6] L. Minhui, Y. Nobuyuki, T. Yumiko et al., "Dual effects of daidzein, a soy isoflavone, on catecholamine synthesis and secretion in cultured bovine adrenal medullary cells," Endocrinology, vol. 148, no. 11, pp. 5348-5354, 2007.

[7] H. Ikeda, S. Matsuyama, N. Suzuki, A. Takahashi, and M. Kuroiwa, "3,4-dihydroxyphenylalanine (DOPA) 
decarboxylase deficiency and resultant high levels of plasma DOPA and dopamine in unfavorable neuroblastoma," $\mathrm{Hy}$ pertension Research, vol. 18, pp. S209-S210, 1995.

[8] M. J. Brown, "Function and regulation of monoamine enzymes: basic and clinical aspects," Febs Letters, vol. 144, no. 2, p. $365,1982$.

[9] H. Zhang, N. Yanagihara, Y. Toyohira et al., "Stimulatory effect of nobiletin, a citrus polymethoxy flavone, on catecholamine synthesis through Ser19 and Ser40 phosphorylation of tyrosine hydroxylase in cultured bovine adrenal medullary cells," Naunyn-Schmiedeberg's Archives of Pharmacology, vol. 387, no. 1, pp. 15-22, 2014.

[10] Y. Nobuyuki, Z. Han, T. Yumiko et al., "New insights into the pharmacological potential of plant flavonoids in the catecholamine system," Journal of Pharmacological Sciences, vol. 124, no. 2, pp. 123-128, 2014.

[11] S. Liwei, X. Yanming, L. Xing et al., "Shenmai injection as an adjuvant treatment for chronic cor pulmonale heart failure: a systematic review and meta-analysis of randomized controlled trials," BMC Complementary \& Alternative Medicine, vol. 15, no. 1, p. 418, 2015.

[12] Z. Haijiang, W. Yongjiang, and C. Yiyu, "Analysis of "SHENMAI" injection by HPLC/MS/MS," Journal of Pharmaceutical and Biomedical Analysis, vol. 31, no. 1, pp. 175183, 2003.

[13] O. E. Olaleye, W. Niu, F.-F. Du et al., "Multiple circulating saponins from intravenous ShenMai inhibit OATP1Bs in vitro: potential joint precipitants of drug interactions," Acta Pharmacologica Sinica, vol. 40, no. 6, pp. 833-849, 2019.

[14] C. Xia, G. Wang, J. Sun et al., "Simultaneous determination of ginsenoside Rg1, Re, Rd, Rb1 and ophiopogonin D in rat plasma by liquid chromatography/electrospray ionization mass spectrometric method and its application to pharmacokinetic study of "SHENMAI" injection," Journal of Chromatography B, vol. 862, no. 1-2, pp. 72-78, 2008.

[15] N.-L. Wang, C.-K. Chang, Y.-L. Liou, C.-L. Lin, and M.-T. Lin, "Shengmai San, a Chinese herbal medicine protects against rat heat stroke by reducing inflammatory cytokines and nitric oxide formation," Journal of Pharmacological Sciences, vol. 98, no. 1, pp. 1-7, 2005.

[16] Z. Guang-Qin, W. Hui, L. Wen-Tao et al., "Long-term treatment with a Chinese herbal formula, Sheng-Mai-San, improves cardiac contractile function in aged rats: the role of $\mathrm{Ca}^{2+}$ homeostasis," Rejuvenation Research, vol. 11, no. 6, pp. 991-1000, 2008.

[17] L. Zhao, J. Wu, X. Zhang et al., "The effect of Shenmai injection on the proliferation of rat airway smooth muscle cells in asthma and underlying mechanism," BMC Complementary \& Alternative Medicine, vol. 13, no. 1, p. 221, 2013.

[18] L. Y. Lu, G. Q. Zheng, and Y. Wang, "An overview of systematic reviews of Shenmai injection for healthcare," Evidence-Based Complementray and Alternative Medicine, vol. 2014, Article ID 840650, 9 pages, 2014.

[19] J. Yu, Y.-F. Xin, L.-Q. Gu et al., "One-month toxicokinetic study of SHENMAI injection in rats," Journal of Ethnopharmacology, vol. 154, no. 2, pp. 391-399, 2014.

[20] M. Haoping, Z. Han, W. Hong et al., "Dual effects of lipophilic extract of Salvia miltiorrhiza (Danshen) on catecholamine secretion in cultured bovine adrenal medullary cells," Journal of Ethnopharmacology, vol. 125, no. 1, pp. 59-67, 2009.

[21] A. Albillos and J. M. McIntosh, "Human nicotinic receptors in chromaffin cells: characterization and pharmacology," Pflügers Archiv-European Journal of Physiology, vol. 470, no. 1, pp. 21-27, 2018.
[22] M. Criado, "Acetylcholine nicotinic receptor subtypes in chromaffin cells," Pflügers Archiv-European Journal of Physiology, vol. 470, no. 1, pp. 13-20, 2018.

[23] C. L. Morales-Perez, C. M. Noviello, and R. E. Hibbs, "X-ray structure of the human $\alpha 4 \beta 2$ nicotinic receptor," Nature, vol. 538, no. 7625, pp. 411-415, 2016.

[24] R. Holz and R. Senter, "Choline stimulates nicotinic receptors on adrenal medullary chromaffin cells to induce catecholamine secretion," Science, vol. 214, no. 4519, pp. 466-468, 1981.

[25] S. Choi, S. Y. Jung, J. H. Lee et al., "Effects of ginsenosides, active components of ginseng, on nicotinic acetylcholine receptors expressed in Xenopus oocytes," European Journal of Pharmacology, vol. 442, no. 1-2, pp. 37-45, 2002.

[26] F. Sala, J. Mulet, S. Choi et al., "Effects of ginsenoside Rg2 on human neuronal nicotinic acetylcholine receptors," Journal of Pharmacology and Experimental Therapeutics, vol. 301, no. 3, pp. 1052-1059, 2002.

[27] A. M. A. Berends, G. Eisenhofer, L. Fishbein et al., "Intricacies of the molecular machinery of catecholamine biosynthesis and secretion by chromaffin cells of the normal adrenal medulla and in Pheochromocytoma and Paraganglioma," Cancers, vol. 11, no. 8, p. 1121, 2019.

[28] P. R. Dunkley and P. W. Dickson, "Tyrosine hydroxylase phosphorylation in vivo," Journal of Neurochemistry, vol. 149, no. 6, pp. 706-728, 2019.

[29] B. Larisa, P. R. Dunkley, and P. W. Dickson, "Phosphorylation of Ser19 increases both Ser40 phosphorylation and enzyme activity of tyrosine hydroxylase in intact cells," Journal of Neurochemistry, vol. 90, no. 4, pp. 857-864, 2010. 